\title{
Precificação no setor supermercadista: uma análise baseada no paradigma estrutura-conduta-desempenho
}

\author{
Giana de Vargas Mores ${ }^{1}$ \\ Caroline Pauletto Spanhol ${ }^{2}$ \\ Dieisson Pivoto $^{3}$ \\ Eduardo Botti Abbade 4
}

Resumo: A partir da concepção da organização industrial e do paradigma estrutura-conduta-desempenho, esta pesquisa objetiva analisar a influência de características específicas (como tamanho e posição geográfica) nos preços praticados pelos estabelecimentos supermercadistas da cidade de Porto Alegre/RS. Foi realizado um levantamento de preços nos estabelecimentos selecionados que considerou 14 produtos de primeira necessidade. Os resultados sugerem que quanto maiores são os estabelecimentos, menores são os preços praticados. Os produtos alimentícios de primeira necessidade apresentaram modelos de regressão mais consistentes.

Palavras-chave: organização industrial; concentração varejista; análise de preços.

JEL: L1; L8; D4.

1 Professora titular do curso de Ciências Econômicas da Universidade Comunitária da Região de Chapecó. Mestre em Agronegócios pela Universidade Federal do Rio Grande do Sul. Especialista em Economia e Gestão Empresarial (2010). E-mail: gimores@gmail.com

2 Professora da Universidade Federal de Mato Grosso do Sul, Campus de Bonito. Mestre em Agronegócios (UFMS) e doutoranda em Agronegócios (UFRGS).E-mail: caroline.spanhol@ufms.br

3 Bolsista de Desenvolvimento Tecnológico e Industrial (DTI-CNPQ) no Ministério da Agricultura, Pecuária e Abastecimento. Mestre em Agronegócios pela Universidade Federal do Rio Grande do Sul. E-mail: dieissonpivoto@gmail.com

4 Professor do Centro Universitário Franciscano e da Faculdade Palotina de Santa Maria - FAPAS. Doutorando em Agronegócios pela Universidade Federal do Rio Grande do Sul - UFRGS. Mestre em Administração pela Universidade Federal do Paraná - UFPR. E-mail: eduardo@unifra.br 
MORES, G.V. et al. Precificação no setor supermercadista: uma análise baseada no paradigma ...

\title{
Pricing in supermarket sector: an analysis based on the Structure-Conduct-Performance paradigm
}

\begin{abstract}
Based on the industrial organization and the structure-conduct-performance paradigm, this work aim to analyze the influence of specific characteristics (such as size and geographical position) in the prices of the supermarkets in Porto Alegre City, State of Rio Grande do Sul. It was surveyed the prices of 14 staple products in the selected points-of-sales. The results suggest that the greater are the enterprises, the lower are the prices. Food staple products presented consistent regression models.
\end{abstract}

Key-words: industrial organization; retailer concentration; price analysis.

JEL: L1; L8; D4.

\section{Introdução}

Os preços praticados pelas firmas têm sido objeto de análise tanto no campo da microeconomia como no da gestão estratégica. Assim, a variável preço assume importância relativa em pesquisas dessa área, principalmente ao considerar a influência que exerce sobre os objetivos da firma e a relação com os concorrentes e os clientes. Nesse sentido, esta pesquisa apresenta pressupostos da Economia Industrial, sobretudo baseados nos trabalhos de Bain (1968) e de Porter (1981).

A partir do entendimento do paradigma estrutura-conduta-desempenho (ECD), surgiu o interesse pela compreensão dos preços praticados pelo setor supermercadista, uma vez que este se apresenta como o principal agente entre a indústria e o consumidor. A função de distribuição assumida e ampliada pelo varejo nos últimos anos tem-lhe conferido grande importância econômica, social e, mais recentemente, ambiental. A importância econômica refere-se aos ganhos financeiros das empresas, o que pode ser exemplificado com a estimativa de que $75 \%$ do faturamento do setor de autosserviço (ganhos equivalentes a $\mathrm{R} \$ 150,4$ bilhões) pertencem ao grupo das 500 maiores empresas supermercadistas, segundo o Ranking Abras 2011. No âmbito social, verifica-se a importância na geração de empregos. As 500 maiores empresas do setor empregam diretamente mais da metade dos colaboradores do segmento de autosserviço, ou seja, 612.898 pessoas (Abras 2011). Na perspectiva ambiental, o varejo tem se destacado na logística reversa de inúmeros itens e na conscientização ambiental, como na diminuição do uso de embalagens plásticas.

O varejo de alimentos, ou seja, o setor supermercadista é caracterizado pela existência de um número reduzido de empresas que detêm boa parte do mercado, tendo a possibilidade de recorrer à competição em preços para ampliar a fatia de mercado. Há também a concorrência com empresas marginais, que são pouco resistentes à eliminação, mas ocupam um espaço considerável no 
mercado. Nesse setor, embora haja alguma oportunidade para diferenciação, a concorrência se realiza predominantemente via preços, o que Possas (1985) define como sendo um oligopólio competitivo.

Os autores Benites e Valério (2004) acrescentam que a competitividade na estrutura do varejo alimentar é de certa maneira desleal, pelo fato de que as empresas líderes possuem infraestrutura capaz de oferecer preços mais atrativos aos consumidores, que, nesse mercado, são considerados mais sensíveis a alterações no preço, provocando um grande esforço na redução de custos por parte das empresas menores. Frente ao exposto, optou-se a analisar o varejo, especificamente o setor supermercadista, a partir da concepção da organização industrial e de seu modelo estrutura-conduta-desempenho, que apresentam aspectos pertinentes para esta análise.

Nesse contexto, esta pesquisa objetiva analisar a influência de características específicas (como tamanho e posição geográfica) nos preços praticados por estabelecimentos do varejo supermercadista da cidade de Porto Alegre/RS. Assim, a análise envolve a coleta de preços de uma cesta de produtos em todos os estabelecimentos varejistas que comercializam alimentos, bebidas e produtos das categorias de higiene e limpeza em todo o bairro selecionado para a pesquisa. O objetivo da análise considera também a verificação de qual é o papel assumido pelo estabelecimento principal na região estudada, no que tange a sua política de preços.

Este artigo está estruturado em seis seções, sendo a primeira esta introdução. A segunda refere-se à revisão teórica dos conceitos da organização industrial. A terceira trata da caracterização do setor supermercadista. A quarta apresenta os procedimentos metodológicos. A quinta apresenta e discute os resultados da pesquisa. Por fim, são apresentadas as conclusões finais.

\section{A organização industrial e o paradigma estrutura-conduta-desempenho}

O referencial teórico abordará os principais assuntos destacados na Organização Industrial, literatura essa que observa os aspectos não considerados pelos economistas clássicos e neoclássicos. As teorias do preço e do equilíbrio geral são contribuições relevantes da economia clássica e também são utilizadas na análise da organização industrial (Bain 1968). A economia ou organização industrial centra-se na análise das relações entre as firmas, dos mercados, das instituições e dos processos (Kupfer \& Hasenclever 2002). Um dos tópicos norteadores dessa abordagem é o modelo estrutura-conduta-desempenho.

Ao se analisar uma firma é importante mencionar conceitos da organização industrial. Entre as funções de uma firma estão o fomento de emprego, a produção de bens e serviços e a distribuição de renda, sendo que o desempenho 
MORES, G.V. et al. Precificação no setor supermercadista: uma análise baseada no paradigma ...

da economia depende fortemente do desempenho das firmas, denominadas por Bain (1968) como firmas de negócios. O mesmo autor discute os determinantes do desempenho de mercado de uma firma, citando a estrutura de mercado e a conduta de mercado. Nesse contexto, Bain (1968) conceitua termos pertinentes para análise:

- firma: organização privada com foco na obtenção de lucro a partir da sua atividade produtiva;

- setor: firmas ou corporações que estão focadas na mesma atividade produtiva, podendo existir pouca concorrência entre as mesmas (por exemplo, agricultura);

- indústria: firmas de um setor específico com algumas funções semelhantes na atividade produtiva de bens e serviços, podendo haver maior diferenciação em resposta à concorrência;

- mercado: grupo de compradores e vendedores fortemente relacionados;

- estrutura de mercado: conjunto de características organizacionais do mercado, as quais configuram como serão as relações entre os agentes econômicos. Nesse caso, pode haver concentração de vendedores, de compradores, de diferenciação de bens e serviços e condição de entrada ao mercado;

- conduta de mercado: comportamento que as firmas adotam na adaptação nos mercados em que situam sua atividade produtiva (por exemplo, como as mesmas estabelecem seus preços);

- desempenho de mercado: resultados que as firmas atingem em um mercado; - workable competition: operação da economia na promoção do bem-estar da sociedade. A busca de um modelo ideal de funcionamento decorrente da adaptação das firmas nos mercados em que atuam.

O autor destaca a importância que a influência da estrutura de mercado tem para conduta de mercado e, assim, para o desempenho do mesmo (Bain 1968). A Figura 1 expressa essa concepção do autor. Nesse momento da literatura, aparecem discussões sobre o paradigma estrutura-conduta-desempenho (ECD).

Em pauta está o questionamento sobre quais as principais decisões que uma empresa deve tomar. Nesse sentido, a determinação dos preços aparece como uma decisão central (nesse ponto, o lucro aparece como resultado da principal decisão), sendo essa fortemente influenciada pela estrutura de mercado na qual a empresa está inserida. Esse é o contexto em que o presente trabalho está inserido. 
FIGURA 1. MODELO ESTRUTURA-CONDUTA-DESEMPENHO

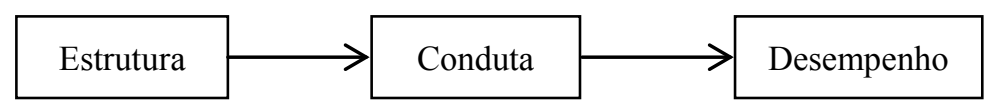

Fonte: Elaborada pelos autores com base em Bain (1968).

Porter (1981) sugere a utilização dos principais conceitos da Economia Industrial na gestão estratégica das organizações. Assim como Bain (1968), Porter (1981) discute questões relacionadas à estrutura de mercado, à conduta das empresas e ao desempenho. A conduta das empresas estaria associada à forma como uma empresa busca competir em seu ambiente, envolvendo decisões sobre produtos, preços, mercados, produção e objetivos organizacionais. Assim, a conduta das empresas adquire caráter estratégico que emerge da necessidade de ajudar o gestor a transformar e organizar as atividades rotineiras e as decisões em uma forma clara para agir frente ao seu ambiente (Porter 1981).

A gestão estratégica surge como uma nova promessa da organização industrial (Porter 1981). Diante disso, emerge o que o autor denominou de unidades de análise. Foram identificados grupos estratégicos que são representados por empresas dentro das indústrias, as quais podem ser agrupadas de acordo com as estratégias praticadas, em que as reações aos distúrbios e o padrão de rivalidade serão determinados pela configuração dos grupos. A diferença nos desempenhos dessas empresas pode estar na existência das barreiras de mobilidade e essa, por sua vez, poderia proporcionar uma base conceitual para o posicionamento da empresa dentro da firma. Cabe mencionar que o desempenho das empresas poderia ser influenciado pela conduta adotada e pela estrutura de mercado na qual a firma está inserida.

A gestão estratégica acrescenta também a utilização de modelos dinâmicos de análise, do ponto de vista da decisão estratégica que a empresa enfrenta. Por fim, essa promessa envolve a inclusão de modelos de análise em que o desempenho anterior da firma afeta as opções estratégicas disponíveis e o feedback da conduta da empresa (Porter 1981). Nesse sentido e considerando a firma como um agente ativo e dinâmico, pode-se dizer que a mesma tem possibilidade de alterar a estrutura de mercado a partir da conduta adotada. Complementarmente, Ferguson e Ferguson (1994) discutem que a boa conduta é aquela que afeta o desempenho da firma que, por sua vez, afeta a estrutura. Assim, observam também que são possíveis outras ligações além do fluxo tradicional da ECD, como por exemplo: i) a estrutura pode afetar o desempenho; ii) o desempenho pode influenciar a conduta; iii) o desempenho pode afetar a estrutura de mercado (retroalimentação).

No momento em que questões relacionadas à conduta das firmas (estratégias) são discutidas, emerge o conceito de competitividade, a qual é um motivador para a adoção de determinadas posturas empresariais. A competitividade pode ser entendida como a habilidade ou o talento resultante de conhecimentos 
adquiridos capazes de criar e sustentar um desempenho superior ao desenvolvido pela concorrência (Porter 1989).

Ainda em relação à estratégia, destaca-se que, para Henderson (1998), o conceito envolve a busca por ações estratégicas para desenvolver e ajustar a vantagem competitiva de uma empresa, cujo objetivo principal é a expansão de mercado $^{1}$, aumentando o escopo de sua vantagem. $\mathrm{O}$ autor defende que quanto mais rico o ambiente competitivo, maior o número de variáveis capazes de proporcionar uma vantagem exclusiva, no entanto, mais acirrada será a concorrência (Benites \& Valério 2004). Para se compreender melhor a competitividade é necessário estudar a indústria, elemento esse fundamental a ser diagnosticado, uma vez que, de acordo com a estrutura da indústria, define-se a estratégia competitiva que possa garantir um desempenho superior. Portanto, a estratégia competitiva adotada depende muito do conhecimento detalhado da estrutura da indústria (Benites \& Valério, 2004).

Porter (1989) condiciona a natureza da competitividade em cinco forças competitivas. A ação dessas forças competitivas determina um desempenho superior, pois elas fixam os preços que as empresas podem cobrar, os custos que têm de suportar e o investimento necessário para competir. O poder de cada força competitiva é também função da estrutura da indústria. As cinco forças podem ser resumidas em: ameaça de novos entrantes, competidores existentes, ameaça de produtos substitutos, poder de barganha dos fornecedores e poder de barganha dos consumidores. Anteriores à análise das cinco forças, Porter (1981) sugere a consideração de quatro elementos chaves para a formulação efetiva da estratégia: i) a análise das forças e fraquezas da empresa, ii) os valores pessoais dos gestores, iii) oportunidades e ameaças da indústria, iv) expectativas da sociedade. $\mathrm{O}$ autor destaca que para a efetiva implantação das estratégias se faz necessária a análise desses elementos.

\section{Panorama sobre o setor supermercadista}

O segmento supermercadista assume posição de destaque entre os que compõem o setor varejista. Esse aspecto pode ser confirmado com os dados destacados por Ferreira et al. (2009), de que, no final dos anos 1990, o segmento comercializava $86,1 \%$ dos produtos à venda no setor varejista. Em 2010, o grupo das 50 maiores empresas supermercadistas, conjuntamente, representaram 64\% do faturamento do setor (Abras 2011). O estado de São Paulo aparece em primeiro lugar no setor de supermercados ao se considerar o número de estabelecimentos. Na sequência, os estados do Rio de Janeiro e do Rio Grande do Sul ocupam a segunda e terceira posições, respectivamente (Abras 2011).

1 Possas (1985) realizou uma ampla revisão de literatura e destaca que os objetivos da firma podem ser diferentes, que não estariam relacionados somente com a maximização do lucro. 
No ranking da Associação Brasileira de Supermercados de 2011, as lojas que mais obtiveram crescimento foram as de menor superfície (lojas de até 250 $\mathrm{m}^{2}$ ), as quais totalizaram 2.280 unidades. Em relação à última pesquisa, no que tange às características desses estabelecimentos: o número de check-outs, em média, permaneceu em duas unidades; o mix de produtos obteve um incremento de $18,7 \%$, sendo que a quantidade de itens de não alimentos que ocasionou o referido aumento (Abras 2011). Os estabelecimentos acima de $5.000 \mathrm{~m}^{2}$ não apresentaram avanço significativo, totalizando apenas 245 unidades dentre as empresas participantes do ranking (Abras 2011).

De acordo com Parente (2000), o setor supermercadista brasileiro apresenta-se desenvolvido e acompanha as tendências do mercado para atender às necessidades e às expectativas do consumidor. Os supermercados podem ser definidos como lojas com o método de autosserviço no varejo de alimentos (Rojo 1998). Os produtos oferecidos pelos mesmos incluem uma ampla variedade de itens, como: mercearia, carnes, hortifrutigranjeiros, frios, laticínios, perfumaria, produtos de limpeza, entre outros. Destaca-se que os hipermercados comercializam também produtos eletrônicos. Contudo, os estabelecimentos de autosserviço do setor supermercadista podem ser classificados de acordo com características mercadológicas (como área de vendas, número de itens comercializados, número de check-outs), como pode ser observado na Tabela 1.

Ampliando algumas descrições da Tabela 1, a partir de Parente (2000), destaca-se que os minimercados contemplam o varejo de alimentos presente nos bairros (geralmente, de classe baixa) com sistema de autosserviço e um check-out. Esses, por sua vez, representam cerca de 10\% dos gastos feitos no varejo supermercadista. As lojas de conveniência, modelo estadunidense dos anos de 1980, localizam-se em postos de combustíveis. A maioria dos estabelecimentos de autosserviço no Brasil é caracterizada pelos supermercados compactos, com estimativa de $25 \%$ da distribuição alimentícia do país.

Os supermercados convencionais apresentam um porte médio e, geralmente, em formato de redes. As superlojas são grandes supermercados com uma linha completa de produtos perecíveis e boa quantidade de produtos não alimentícios. Nos hipermercados, os preços são mais competitivos, sendo a área maior destinada aos produtos não alimentícios a principal diferença em relação à superloja. Os clubes atacadistas são grandes lojas que vendem no varejo e no atacado, conhecidos também como atacarejos, os quais têm sortimento compacto, instalações simples e preços baixos.

O papel dos supermercados no varejo de alimentos está atrelado às vantagens de custos associadas a esse tipo de varejo, como: economias de escala devido à ampliação da área de vendas; economias de multiplanta decorrentes da centralização de atividades em empresas com várias lojas; economias pecuniárias associadas ao maior poder de barganha decorrente do volume de compras (Cyrillo 1987). 
TABELA 1. CARACTERIZAÇÃO DOS FORMATOS DO SETOR SUPERMERCADISTA

\begin{tabular}{|c|c|c|c|c|c|}
\hline Formato & $\begin{array}{l}\text { Áreas de } \\
\text { venda } \\
\left(\mathrm{m}^{2}\right)\end{array}$ & $\begin{array}{l}\mathrm{N}^{\circ} \text { médio } \\
\text { de itens }\end{array}$ & $\begin{array}{c}\text { \% não } \\
\text { alimentos }\end{array}$ & $\begin{array}{l}\mathrm{N}^{\circ} \text { de } \\
\text { check } \\
\text { outs }\end{array}$ & Setores \\
\hline Bares $^{\text {a }}$ & $20-50$ & 300 & 1 & - & $\begin{array}{c}\text { mercearia, lanches e } \\
\text { bebidas }\end{array}$ \\
\hline Mercearias $^{\text {a }}$ & $20-50$ & 500 & 3 & - & $\begin{array}{l}\text { mercearia, frios, } \\
\text { laticínios e bazar }\end{array}$ \\
\hline Padaria $^{a}$ & $50-100$ & 1.000 & 1 & - & $\begin{array}{l}\text { padaria, mercearia, } \\
\text { frios, laticínios e } \\
\text { lanches }\end{array}$ \\
\hline Minimercado & $50-100$ & 1.000 & 3 & 1 & $\begin{array}{l}\text { mercearia, frios, } \\
\text { laticínios e bazar }\end{array}$ \\
\hline $\begin{array}{l}\text { Loja de } \\
\text { conveniência }\end{array}$ & $50-250$ & 1.000 & 3 & $1-2$ & $\begin{array}{l}\text { mercearia, frios, } \\
\text { laticínios, bazar e } \\
\text { lanches }\end{array}$ \\
\hline $\begin{array}{l}\text { Supermercado } \\
\text { compacto }\end{array}$ & $\begin{array}{l}300- \\
700\end{array}$ & 4.000 & 3 & $2-6$ & $\begin{array}{c}\text { mercearia, } \\
\text { hortifrutigranjeiros, } \\
\text { carnes, aves, frios, } \\
\text { laticínios e bazar }\end{array}$ \\
\hline $\begin{array}{l}\text { Supermercado } \\
\text { convencional }\end{array}$ & $\begin{array}{l}700- \\
2.500\end{array}$ & 9.000 & 6 & $7-20$ & $\begin{array}{c}\text { mercearia, } \\
\text { hortifrutigranjeiros, } \\
\text { carnes, aves, peixes, } \\
\text { frios, laticínios e } \\
\text { bazar }\end{array}$ \\
\hline $\begin{array}{l}\text { Supermercado } \\
\text { de proximidade }\end{array}$ & $150-300$ & 4.000 & 1 & $3-4$ & $\begin{array}{c}\text { mercearia, } \\
\text { carnes, aves, } \\
\text { hortifrutigranjeiros, } \\
\text { frios, laticínios e } \\
\text { bazar }\end{array}$ \\
\hline Superloja & $\begin{array}{c}2.500- \\
5.000\end{array}$ & 14.000 & 12 & $25-36$ & $\begin{array}{l}\text { mercearia, } \\
\text { hortifrutigranjeiros, } \\
\text { carnes, aves, peixes, } \\
\text { frios, laticínios, } \\
\text { padaria, bazar, têxtil } \\
\text { e eletrônico }\end{array}$ \\
\hline Hipermercado & $\begin{array}{l}7.000- \\
16.000\end{array}$ & 45.000 & 30 & $55-90$ & $\begin{array}{l}\text { mercearia, } \\
\text { hortifrutigranjeiros, } \\
\text { carnes, aves, peixes, } \\
\text { frios, laticínios, } \\
\text { padaria, bazar, têxtil } \\
\text { e eletrônico }\end{array}$ \\
\hline Clube atacadista & $\begin{array}{l}5.000- \\
12.000\end{array}$ & 5.000 & 35 & $25-35$ & $\begin{array}{l}\text { mercearia, } \\
\text { hortifrutigranjeiros, } \\
\text { carnes, aves, frios, } \\
\text { laticínios, padaria, } \\
\text { bazar, têxtil e } \\
\text { eletrônico }\end{array}$ \\
\hline
\end{tabular}

Fonte: Elaborada pelos autores com base em Parente (2000).

Nota: a) Geralmente são formatos que não utilizam check outs. 
Os mercados maiores possuem vantagens no que se refere à questão de custos, os quais podem ser reduzidos no ato de grandes negociações com fornecedores. Isso justifica o fato de praticarem um preço menor em seus produtos. Os mercados de pequeno porte apresentam vantagens em relação à localização. Entretanto, à medida que os mesmos aproximam-se dos mercados de grande porte, as vantagens referentes à localização tendem a desaparecer, havendo assim a necessidade de modificarem sua conduta de preços para conseguirem um desempenho melhor.

Com base na aplicação dos conceitos da organização industrial, pode-se classificar a estrutura de mercado presente no setor supermercadista brasileiro como um oligopólio competitivo em franja (Cyrillo 1987). Define-se o oligopólio competitivo em franja como uma estrutura de mercado com elevada concentração, grande número de pequenas e médias empresas que formam uma franja competitiva (Farina 2000). Em geral, as barreiras à entrada são baixas nessa estrutura, porém, o mesmo não ocorre para as barreiras de mobilidade.

\section{Procedimentos metodológicos}

O enquadramento metodológico e as técnicas de pesquisa seguem a classificação proposta por Gil (2010). As pesquisas exploratória e descritiva são utilizadas nesta pesquisa. De acordo com os métodos empregados, a natureza dos dados se enquadra na abordagem quantitativa, sendo os dados coletados por meio da pesquisa de campo. Configura-se também a utilização das pesquisas bibliográfica e documental.

Em consideração ao caso a ser analisado, deve-se fazer menção à cidade de Porto Alegre, sendo a capital do estado do Rio Grande do Sul com uma população (ano 2010) de 1.409.351 habitantes (Ibge 2012) e apresentando um produto interno bruto per capita de $\mathrm{R} \$ 26.312,00$ no ano de 2009 (Fee 2012). O município é formado por 81 bairros oficiais (Porto Alegre 2012), sendo que o bairro escolhido para a coleta de dados desta pesquisa possui cerca de 16.50o habitantes e de 7.800 domicílios (ano 2010), passando pelo mesmo 19 ruas e 07 avenidas numa área total de 210 hectares (Porto Alegre 2012).

O bairro foi selecionado por meio do julgamento dos pesquisadores levando em consideração importantes características: situa-se na região central de Porto Alegre, possui elevado fluxo de pessoas, os moradores pertencem a diferentes classes sociais. Além disso, há a presença de um hipermercado considerado como estabelecimento principal em virtude do tamanho de sua área de vendas. Os nomes e endereços dos estabelecimentos serão preservados, os quais foram pesquisados na lista telefônica online na categoria supermercado da cidade de Porto Alegre e pela busca na ferramenta Googlemaps. Não foi possível o acesso ao cadastro dos estabelecimentos do bairro pertencentes à 
Associação Gaúcha de Supermercados (AGAS). Depois disso, percorreram-se todas as ruas e avenidas do bairro para a identificação dos empreendimentos do varejo de alimentos. Assim, foram localizados 15 estabelecimentos para o levantamento de dados.

Depois de levantados os locais para a coleta de dados, foram calculadas as distâncias em metros, partindo do hipermercado como ponto de origem. Não foi feita exclusão por tamanho/porte dos mercados. Os preços dos produtos foram coletados no momento da visita em cada estabelecimento. A aplicação do instrumento de coleta de dados ocorreu entre os dias 04 e 10 de janeiro de 2012. Além dos preços dos produtos, foram coletados os números de check outs (caixas) de cada estabelecimento como forma de mensurar o tamanho dos mesmos.

Para fins de comparativo de preços, os produtos a terem seus preços coletados foram embasados na lista de produtos da cesta básica da Associação Gaúcha de Supermercados (2012). A partir do julgamento dos pesquisadores, 14 produtos foram selecionados de acordo com a sua relevância de uso no cotidiano da população. As marcas escolhidas seguiram a ideia de popularidade no sentido de serem as mais conhecidas e utilizadas pelo público em geral, as quais também foram definidas a partir do julgamento dos pesquisadores. $\mathrm{O}$ fato de cada um dos produtos ser da mesma marca na coleta dos preços atende à finalidade de manter a padronização dos itens pesquisados. A relação dos produtos pesquisados é: açúcar refinado (1 quilo), arroz (1 quilo), cebola (1 quilo), refrigerante (2 litros), farinha de trigo (1 quilo), leite integral (1 litro); massa com ovos (o,50 quilo), molho de tomate (o,26 quilo), óleo de soja (1 litro), ovos de granja brancos (1 dúzia), sabão em pó (1 quilo), sabonete (1 barra), xampu (o, 35 litro), tomate longa vida (1 quilo).

Para a análise e interpretação dos dados foram empregadas as técnicas estatísticas: análise descritiva, análise de regressão múltipla e gráficos de superfície. A análise descritiva foi feita por meio da observação da soma dos preços coletados dos 14 produtos em cada um dos estabelecimentos. Somado a isso, são apresentados o número de caixas e de colaboradores e a distância do estabelecimento focal (A) para cada um dos demais estabelecimentos analisados. Ressalta-se que os preços de alguns produtos não foram encontrados em todos os mercados. Assim, os dados faltantes foram completados pela média de preço obtida nos demais estabelecimentos para determinado produto. Os cálculos estatísticos e a elaboração dos gráficos de superfície foram feitos com o auxílio do software Statistica 8.0.

\section{Resultados e discussões}

Esta seção contempla os resultados obtidos na investigação desta pesquisa. Inicialmente, na Tabela 2, são apresentados os dados de cada um dos esta- 
belecimentos pesquisados. O mercado A foi definido como a empresa focal em virtude de seu tamanho e da movimentação comercial vista diariamente a partir da observação dos pesquisadores. O nome e a localização dos estabelecimentos não serão divulgados, a fim de se manter o anonimato daqueles que participaram da pesquisa. Assim, os 15 mercados estão identificados por letras maiúsculas em ordem alfabética.

Por meio da observação das informações da Tabela 2, constata-se que o mercado A é o maior mercado e o que apresenta a menor soma de preços dos produtos pesquisados $(\mathrm{R} \$ 35,67)$. Em contrapartida, os estabelecimentos $\mathrm{Fe}$ N obtiveram os preços mais elevados, $\mathrm{R} \$ 49,46$ e $\mathrm{R} \$ 49,06$, respectivamente. O número de caixas é utilizado como variável para a definição do tamanho dos estabelecimentos, observando-se uma grande amplitude na distribuição dessa variável. A maioria dos mercados possui apenas um caixa. Os dois maiores, os mercados A e D, apresentam 21 e 20 caixas, nessa ordem. O número de colaboradores apresentou variabilidade, sendo que alguns estabelecimentos não disponibilizaram essa informação. O serviço de entrega de compras em domicílio é fornecido por $60 \%$ dos mercados, ou seja, por o9 estabelecimentos. As distâncias existentes entre os estabelecimentos pesquisados e o mercado focal (A) foram calculadas, sendo feitas com o auxílio do Google Maps (distância a ser percorrida na modalidade de caminhada). Para tanto, foram definidas as coordenadas para os estabelecimentos pesquisados, a fim de se elaborar um mapa de superfície. (continuação)

TABELA 2. CARACTERIZAÇÃO DOS ESTABELECIMENTOS PESQUISADOS

\begin{tabular}{|c|c|c|c|c|c|c|c|}
\hline $\begin{array}{c}\text { Esta- } \\
\text { bel. }\end{array}$ & $\begin{array}{l}\text { Total } \\
(\mathrm{R} \$)\end{array}$ & $\begin{array}{l}\mathrm{N}^{\mathrm{o}} \mathrm{de} \\
\text { caixas }\end{array}$ & $\begin{array}{l}\text { Colabo- } \\
\text { radores }\end{array}$ & $\begin{array}{l}\text { Entrega na } \\
\text { residência a }\end{array}$ & $\begin{array}{l}\text { Distância } \\
\text { (m) }\end{array}$ & $\begin{array}{c}\text { Coor- } \\
\text { denada } \\
x^{b}\end{array}$ & $\begin{array}{c}\text { Coor- } \\
\text { denada } \\
\mathrm{y}^{\mathrm{b}} \\
\end{array}$ \\
\hline $\mathbf{A}$ & 35,67 & 21 & nd & 1 & o & 109 & 66 \\
\hline B & 38,37 & 7 & nd & o & 400 & 74 & 88 \\
\hline C & 45,37 & 1 & 2 & 1 & 400 & 82 & 48 \\
\hline D & 38,43 & 20 & nd & o & 900 & 50 & 24 \\
\hline $\mathbf{E}$ & 47,03 & 1 & nd & 1 & 450 & 132 & 26 \\
\hline $\mathbf{F}$ & 49,46 & 1 & 4 & 1 & 600 & 122 & 5 \\
\hline $\mathbf{G}$ & 48,08 & 1 & 5 & 1 & 650 & 98 & 7 \\
\hline $\mathbf{H}$ & 46,50 & 1 & 3 & 1 & 400 & 79 & 70 \\
\hline I & 46,80 & 1 & 6 & 1 & 550 & 75 & 99 \\
\hline $\mathbf{J}$ & 47,51 & 1 & 2 & o & 600 & 51 & 77 \\
\hline $\mathbf{K}$ & 43,76 & 1 & 2 & o & 600 & 50 & 62 \\
\hline $\mathbf{L}$ & 46,16 & 1 & 2 & o & 800 & 50 & 30 \\
\hline
\end{tabular}


TABELA 2 (continuação). CARACTERIZAÇÃO DOS ESTABELECIMENTOS PESQUISADOS

\begin{tabular}{llcccccc}
\hline $\mathbf{M}$ & 46,06 & 1 & 1 & 1 & 260 & 102 & 97 \\
$\mathbf{N}$ & 49,06 & 1 & 1 & 1 & 1200 & 4 & 43 \\
$\mathbf{O}$ & 46,56 & 1 & 2 & 0 & 450 & 115 & 13 \\
\hline
\end{tabular}

Fonte: Dados da pesquisa (2012)

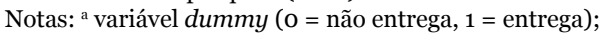

${ }^{\mathrm{b}}$ as coordenadas foram calculadas sobre o mapa do recurso Google Maps, para fins de elaboração gráfica; nd = dados não disponíveis.

A Tabela 3 traz os dados descritivos obtidos para os preços dos produtos pesquisados, em que são mostrados os valores: da média, dos preços mínimos e máximos, do desvio padrão e do coeficiente de variação para a distribuição de preços de cada um dos produtos.

TABELA 3. DADOS DESCRITIVOS DOS ESTABELECIMENTOS PESQUISADOS

\begin{tabular}{l|c|c|c|c|c}
\hline \multicolumn{1}{c|}{ Produto } & $\begin{array}{c}\text { Média } \\
(\mathrm{R} \$)\end{array}$ & $\begin{array}{c}\text { Mínimo } \\
(\mathrm{R} \$)\end{array}$ & $\begin{array}{c}\text { Máximo } \\
(\mathrm{R} \$)\end{array}$ & $\begin{array}{c}\text { Desvio } \\
\text { padrão }\end{array}$ & $\begin{array}{c}\text { Coeficiente de } \\
\text { variação (\%) }\end{array}$ \\
\hline Açúcar refinado & 2,91 & 2,25 & 3,65 & 0,45 & 15,51 \\
Arroz & 2,68 & 1,95 & 3,45 & 0,39 & 14,53 \\
Cebola & 1,52 & 0,98 & 2,00 & 0,39 & 25,62 \\
Refrigerante de & 4,18 & 3,39 & 4,90 & 0,47 & 11,15 \\
cola & & & & & \\
Farinha de trigo & 1,99 & 1,59 & 2,49 & 0,28 & 13,94 \\
Leite integral & 2,13 & 1,47 & 2,50 & 0,38 & 17,66 \\
Massa com ovos & 2,56 & 1,90 & 2,98 & 0,40 & 15,79 \\
Molho de tomate & 2,34 & 2,09 & 2,60 & 0,10 & 4,11 \\
Óleo de soja & 3,60 & 2,65 & 4,20 & 0,49 & 13,61 \\
Ovos de granja & 2,97 & 2,50 & 3,85 & 0,30 & 10,26 \\
brancos & & & & & 0,95 \\
Sabão em pó & 7,22 & 5,38 & 8,75 & 0,95 & 13,13 \\
Sabonete & 1,14 & 0,79 & 1,49 & 0,19 & 17,08 \\
Xampu & 6,15 & 4,79 & 6,99 & 0,58 & 9,38 \\
Tomate longa vida & 3,60 & 2,95 & 4,50 & 0,61 & 16,92 \\
\hline
\end{tabular}

Fonte: Dados da pesquisa (2012). 
Os valores de média, mínimo, máximo e desvio padrão não permitem conclusões robustas a respeito dos preços coletados. Entretanto, esses valores fornecem um panorama dos preços dos produtos praticados pelos 15 mercados pesquisados. O valor do coeficiente de variação permite avaliar o grau de variação de preços observados nos estabelecimentos. Assim, pode-se afirmar que a cebola $(\mathrm{kg})$ foi o produto que mostrou a maior variação de preços $(25,62 \%)$ entre os mercados. O molho de tomate e o xampu foram os produtos que tiveram menor variabilidade de preços (4,11\% e 9,38\%, nessa ordem). No entanto, ressalta-se que os preços do molho de tomate não foram coletados em todos os mercados, a falta de dados justifica-se pela diversidade de marcas encontradas na coleta. Com isso, as informações obtidas para esse produto devem ser observadas com certa limitação conclusiva. Os demais produtos obtiveram variabilidades moderadas e semelhantes.

Nesse momento, a pesquisa direciona-se à explicação sobre o que pode levar a essa variabilidade de preços. Primeiramente, as somas dos preços dos produtos coletados em cada um dos estabelecimentos estão evidenciadas no gráfico de superfície da Figura 2, elaborado juntamente com as coordenadas estabelecidas (Tabela 2) para cada estabelecimento.

FIGURA 2. ANÁLISE DE SUPERFÍCIE DA SOMA DOS PREÇOS (R\$) DOS PRODUTOS PESQUISADOS (POR ESTABELECIMENTO)
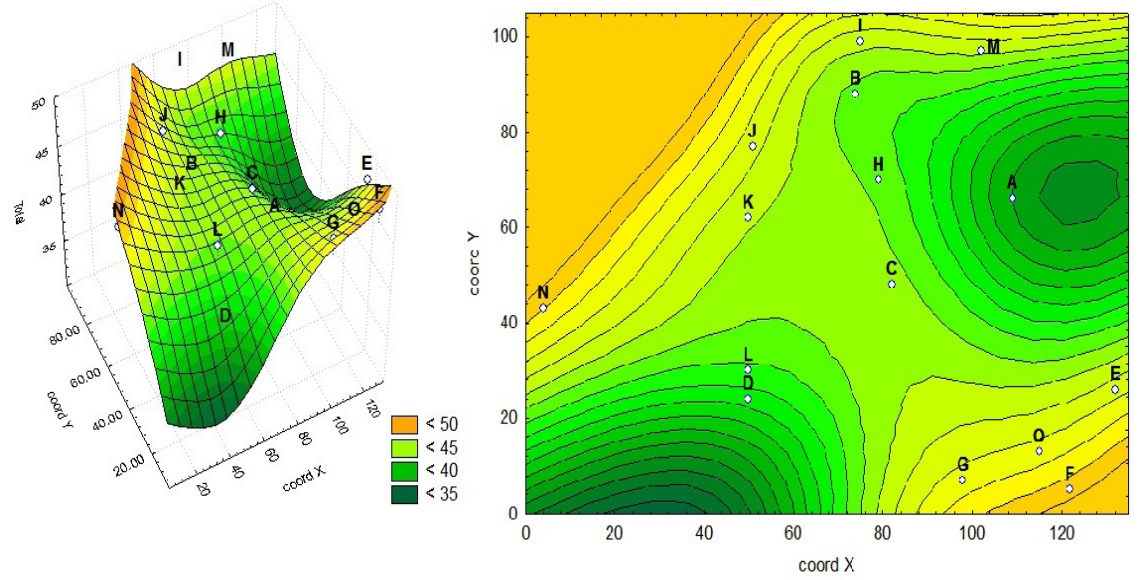

Fonte: Dados da pesquisa (2012).

Considerando o estabelecimento A como mercado focal, pode-se observar que o mesmo apresenta uma soma de preços inferior aos demais. Essa evidência sugere que o mercado de maior porte e de movimentação é o que apresenta os menores preços. Observa-se que o estabelecimento D (o segundo maior estabelecimento) também mostra uma soma de preços inferior aos demais, inferindo-se que o estabelecimento aparece como resposta às práticas exer- 
cidas pelo mercado focal. Tomando-se os mercados A e D como os pontos de menor preço, verifica-se que, conforme ocorre um afastamento geográfico dos dois pontos, os mercados tendem a cobrar preços mais elevados nos produtos considerados nesta análise. O estabelecimento B é o terceiro maior da pesquisa e está mais próximo do mercado A. Cabe destacar que os mercados A e D pertencem a redes de hipermercados, os quais detêm boa parcela do mercado consumidor da cidade analisada, característica essa que auxilia a configurar a estrutura de mercado: oligopólio. No Ranking Abras (2011), os estabelecimentos A e D figuram entre a lista das 10 maiores redes supermercadistas do Brasil.

Ainda em menção à Figura 2, evidencia-se uma aglomeração de mercados formada pelos estabelecimentos $\mathrm{E}, \mathrm{G}, \mathrm{O}$ e F, os quais apresentam preços mais elevados e distâncias semelhantes e relativamente altas dos mercados de maior porte. Outros estabelecimentos mais afastados dos maiores, como os representados pelas letras N, I, J e K, praticam preços superiores. O mercado M, próximo ao A, mostra uma soma de preços muito superior, inferindo-se que pode haver uma possível falha estratégica de posicionamento de preços. Assim, deduz-se que os mercados de menor porte concorrem entre si.

Na sequência, os resultados das análises de regressões múltiplas estão dispostos na Tabela 4. Foram realizadas 15 regressões, em que as variáveis dependentes foram os preços dos 14 produtos pesquisados e a soma total dos preços dos produtos coletados em cada mercado. As variáveis independentes das regressões foram: o número de caixas dos estabelecimentos, a possibilidade de entrega em domicílio (variável dummy: $\mathrm{o}=$ não entrega, 1 = entrega) e a distância do mercado focal de maior porte (A). O número de colaboradores não foi considerado pelo fato de existirem dados faltantes e baixa variância.

Observando os resultados da primeira regressão, na qual a variável dependente é a soma dos preços dos produtos pesquisados, constata-se que a regressão é significativa ( $\mathrm{p}<\mathrm{0}, 001)$ e as variáveis independentes do modelo explicam $84,81 \%$ da variação de preços dos mercados. Ao se considerar as variáveis independentes, as evidências sugerem que o tamanho do estabelecimento exerce uma influência significativa e negativa no preço dos produtos analisados. Assim, quanto maior é o tamanho do mercado, menor é a soma do preço total dos produtos. A entrega em domicílio também influencia significativamente no preço $(\mathrm{p}=0,034)$ e de forma positiva. Nesse contexto, os mercados que disponibilizam esse serviço complementar tendem a cobrar um preço mais elevado pelos produtos ofertados. A última variável independente (distância do mercado focal) apresenta uma relação significativa e positiva $(p=0,020)$, sugerindo que os mercados mais afastados do focal tendem a cobrar mais pelos produtos.

Analisando os resultados da regressão que têm como variável dependente o preço do açúcar refinado, observa-se que a regressão é significativa $(\mathrm{p}<0,001)$ e explica $78,43 \%$ da variação do preço desse produto. Quanto às variáveis 
independentes do modelo, é possível constatar que o tamanho dos estabelecimentos influencia significativa $(\mathrm{p}=0,003)$ e negativamente no preço do açúcar refinado. A possibilidade de entrega em domicílio e a distância do mercado focal influenciam de forma positiva e significativa no preço do açúcar ( $\mathrm{p}=0,001$ e $\mathrm{p}=0,005$, respectivamente). $\mathrm{O}$ terceiro modelo de regressão tem como variável dependente o preço do arroz, o qual obteve significância estatística $(\mathrm{p}<0,001)$ e explica $71,48 \%$ da variação do preço do produto em questão. A partir das variáveis independentes, observa-se que o tamanho dos mercados exerce influência negativa e significativa $(\mathrm{p}=0,007)$ nos preços cobrados pelo arroz, assim como a distância do mercado focal $(\mathrm{p}=0,002)$. Já a entrega em domicílio não influencia significativamente no preço do produto.

\section{TABELA 4. ANÁLISES DE REGRESSÃO MÚLTIPLA}

\begin{tabular}{|c|c|c|c|c|c|c|}
\hline & & $\beta$ & $\begin{array}{l}\text { Erro padrão } \\
\text { do } \beta\end{array}$ & p-valor & $\begin{array}{c}\mathrm{R}^{2} \text { ajus- } \\
\text { tado }\end{array}$ & $\begin{array}{l}\mathrm{p} \text {-valor da } \\
\text { regressão }\end{array}$ \\
\hline \multirow{4}{*}{ Total } & Intercepto & 43,127 & 1,327 & 0,000 & \multirow{4}{*}{0,8481} & \multirow{4}{*}{$\mathrm{p}<0, \mathrm{oO} 1$} \\
\hline & Número de caixas & $-0,471$ & 0,066 & 0,000 & & \\
\hline & Entrega na residência & 2,171 & 0,895 & 0,034 & & \\
\hline & Distância & 0,004 & 0,002 & 0,020 & & \\
\hline \multirow{4}{*}{$\begin{array}{l}\text { Açúcar } \\
\text { refinado }\end{array}$} & Intercepto & 2,340 & 0,172 & 0,000 & \multirow{4}{*}{0,7843} & \multirow{4}{*}{$\mathrm{p}<0,001$} \\
\hline & Número de caixas & $-0,033$ & 0,008 & 0,003 & & \\
\hline & Entrega na residência & 0,506 & 0,116 & 0,001 & & \\
\hline & Distância & o,o01 & 0,000 & 0,005 & & \\
\hline \multirow{4}{*}{ Arroz } & Intercepto & 2,184 & 0,170 & 0,000 & \multirow{4}{*}{0,7148} & \multirow{4}{*}{$\mathrm{p}<\mathrm{o}, \mathrm{oO} 1$} \\
\hline & Número de caixas & $-0,028$ & 0,008 & 0,007 & & \\
\hline & Entrega na residência & 0,232 & 0,115 & 0,067 & & \\
\hline & Distância & 0,001 & 0,000 & 0,002 & & \\
\hline \multirow{4}{*}{ Cebola } & Intercepto & 1,533 & 0,324 & 0,001 & \multirow{4}{*}{-} & \multirow{4}{*}{$\mathrm{p}=0,511$} \\
\hline & Número de caixas & $-0,020$ & 0,016 & 0,245 & & \\
\hline & Entrega na residência & $-0,100$ & 0,219 & 0,657 & & \\
\hline & Distância & 0,000 & 0,000 & 0,589 & & \\
\hline \multirow{4}{*}{$\begin{array}{l}\text { Refrige- } \\
\text { rante de } \\
\text { cola }\end{array}$} & Intercepto & 4,085 & 0,266 & 0,000 & \multirow{4}{*}{0,5128} & \multirow{4}{*}{$\mathrm{p}<0,050$} \\
\hline & Número de caixas & $-0,046$ & 0,013 & 0,005 & & \\
\hline & Entrega na residência & 0,079 & 0,179 & 0,669 & & \\
\hline & Distância & 0,000 & 0,000 & 0,223 & & \\
\hline \multirow{4}{*}{$\begin{array}{l}\text { Farinha } \\
\text { de trigo }\end{array}$} & Intercepto & 1,859 & 0,182 & 0,000 & \multirow{4}{*}{ o,3556 } & \multirow{4}{*}{$\begin{array}{c}\mathrm{p}= \\
\mathrm{o,0504}\end{array}$} \\
\hline & Número de caixas & $-0,022$ & 0,009 & 0,035 & & \\
\hline & Entrega na residência & 0,171 & 0,123 & 0,193 & & \\
\hline & Distância & 0,000 & 0,000 & 0,360 & & \\
\hline \multirow{4}{*}{ Leite } & Intercepto & 2,106 & 0,187 & 0,000 & \multirow{4}{*}{ o,6333 } & \multirow{4}{*}{$\mathrm{p}<\mathrm{O}, \mathrm{O} 10$} \\
\hline & Número de caixas & $-0,042$ & 0,009 & 0,001 & & \\
\hline & Entrega na residência & 0,051 & 0,126 & 0,691 & & \\
\hline & Distância & o,ooo & o,ooo & 0,219 & & \\
\hline
\end{tabular}


MORES, G.V. et al. Precificação no setor supermercadista: uma análise baseada no paradigma ...

TABELA 4 (continuação). ANÁLISES DE REGRESSÃO MÚLTIPLA

\begin{tabular}{|c|c|c|c|c|c|c|}
\hline \multirow{4}{*}{$\begin{array}{l}\text { Massa } \\
\text { com ovos }\end{array}$} & Intercepto & 2,220 & 0,196 & 0,000 & \multirow{4}{*}{0,6472} & \multirow{4}{*}{$\mathrm{p}<0,010$} \\
\hline & Número de caixas & $-0,032$ & 0,010 & 0,008 & & \\
\hline & Entrega na residência & 0,430 & 0,132 & 0,008 & & \\
\hline & Distância & 0,000 & 0,000 & 0,146 & & \\
\hline \multirow{4}{*}{$\begin{array}{l}\text { Molho de } \\
\text { tomate }\end{array}$} & Intercepto & 2,305 & 0,068 & 0,000 & \multirow{4}{*}{0,2567} & \multirow{4}{*}{$\mathrm{p}=0,1039$} \\
\hline & Número de caixas & $-0,007$ & 0,003 & 0,070 & & \\
\hline & Entrega na residência & 0,002 & 0,046 & 0,972 & & \\
\hline & Distância & 0,000 & 0,000 & 0,182 & & \\
\hline \multirow{4}{*}{$\begin{array}{l}\text { Óleo de } \\
\text { soja }\end{array}$} & Intercepto & 3,405 & 0,231 & 0,000 & \multirow{4}{*}{0,6674} & \multirow{4}{*}{$\mathrm{p}<0,010$} \\
\hline & Número de caixas & $-0,051$ & 0,011 & 0,001 & & \\
\hline & Entrega na residência & 0,211 & 0,156 & 0,204 & & \\
\hline & Distância & 0,000 & 0,000 & 0,111 & & \\
\hline \multirow{4}{*}{$\begin{array}{l}\text { Ovos de } \\
\text { granja } \\
\text { brancos }\end{array}$} & Intercepto & 2,399 & 0,171 & 0,000 & \multirow{4}{*}{0,5270} & \multirow{4}{*}{$\mathrm{p}<0,050$} \\
\hline & Número de caixas & $-0,004$ & 0,008 & 0,657 & & \\
\hline & Entrega na residência & 0,379 & 0,115 & 0,007 & & \\
\hline & Distância & 0,001 & 0,000 & 0,011 & & \\
\hline \multirow{4}{*}{$\begin{array}{l}\text { Sabão } \\
\text { em pó }\end{array}$} & Intercepto & 7,386 & 0,564 & 0,000 & \multirow{4}{*}{0,4700} & \multirow{4}{*}{$\mathrm{p}<0,050$} \\
\hline & Número de caixas & $-0,099$ & 0,028 & 0,005 & & \\
\hline & Entrega na residência & 0,325 & 0,381 & 0,411 & & \\
\hline & Distância & 0,000 & 0,001 & 0,933 & & \\
\hline \multirow{4}{*}{ Sabonete } & Intercepto & 0,997 & 0,110 & 0,000 & \multirow{4}{*}{0,5227} & \multirow{4}{*}{$\mathrm{p}<0,050$} \\
\hline & Número de caixas & $-0,015$ & 0,005 & 0,016 & & \\
\hline & Entrega na residência & 0,160 & 0,074 & $\mathrm{O}, 053$ & & \\
\hline & Distância & 0,000 & 0,000 & 0,187 & & \\
\hline \multirow{4}{*}{ Xampu } & Intercepto & 5,779 & 0,381 & 0,000 & \multirow{4}{*}{0,3487} & \multirow{4}{*}{$\mathrm{p}=0,0533$} \\
\hline & Número de caixas & $-0,042$ & 0,019 & 0,047 & & \\
\hline & Entrega na residência & 0,317 & 0,257 & 0,243 & & \\
\hline & Distância & 0,001 & 0,000 & 0,202 & & \\
\hline \multirow{4}{*}{$\begin{array}{l}\text { Tomate } \\
\text { longa } \\
\text { vida }\end{array}$} & Intercepto & 4,527 & 0,462 & 0,000 & \multirow{4}{*}{0,1391} & \multirow{4}{*}{$p=0,2139$} \\
\hline & Número de caixas & $-0,031$ & 0,023 & 0,196 & & \\
\hline & Entrega na residência & $-0,592$ & 0,312 & 0,084 & & \\
\hline & Distância & $-0,001$ & 0,001 & 0,182 & & \\
\hline
\end{tabular}

Fonte: Dados da pesquisa (2012).

Em relação à Tabela 4, adotou-se, no quarto modelo de regressão, o preço da cebola como variável dependente, sendo que não apresentou significância estatística. Nenhuma das variáveis independentes do modelo apresentou influência significativa no preço do produto. Considera-se, portanto, que essas variáveis não explicam a variação de preços da cebola nos estabelecimentos desta pesquisa. O quinto modelo toma o preço do refrigerante de cola como variável dependente, sendo que demonstra significância estatística $(\mathrm{p}<0,050)$. As variáveis independentes do modelo explicam $51,28 \%$ da variação do preço do produto. Contudo, apenas o tamanho dos estabelecimentos obteve impacto significativo $(\mathrm{p}=0,005)$ e negativo no preço do refrigerante de cola. Assim, quanto maior o porte do mercado, menor é o preço cobrado pelo refrigerante. 
Não foi observado impacto significativo das demais variáveis independentes do modelo.

O sexto modelo de regressão adota o preço da farinha de trigo como variável dependente. $\mathrm{O}$ modelo demonstrou uma consistência estatística fraca ( $\mathrm{p}=\mathrm{o}, 05 \mathrm{0})$, entretanto, considera-se o mesmo válido devido ao seu valor de significância. As variáveis independentes explicam 35,56\% da variação do preço da farinha de trigo, observando-se que apenas o tamanho dos mercados influencia negativa e significativamente $(\mathrm{p}=0,035)$ no preço do produto. Isso significa que, quanto maior é o mercado, menor é o preço cobrado pelo produto. A sétima regressão múltipla realizada tem o preço do leite integral como variável dependente, constatando-se que o modelo é significativo estatisticamente ( $\mathrm{p}<0,010$ ) e explica 63,33\% da variação do preço. Ao analisar o impacto das variáveis independentes no preço do leite, verifica-se que apenas o tamanho dos estabelecimentos exerce influência significativa e negativa no preço do produto, ou seja, estabelecimentos maiores tendem a cobrar menos por tal produto. As outras duas variáveis independentes não apresentaram significância estatística.

A regressão tendo o preço da massa com ovos como variável dependente demonstrou significância estatística $(\mathrm{p}<0,01)$ e explica $64,72 \%$ da variação do preço do produto. Dentre as variáveis independentes do modelo, o tamanho do estabelecimento teve significância estatística $(\mathrm{p}=0,008)$ e influência negativa no preço. O serviço de entrega em domicílio também apresentou significância ( $\mathrm{p}=\mathrm{o}, 008$ ), porém positiva. Dessa forma, estabelecimentos maiores cobram preços menores pelo produto. Em contrapartida, mercados com entrega em domić́lio cobram preços mais altos pelo mesmo. O nono modelo de regressão considerou como variável dependente o preço do molho de tomate. Apesar de não ter apresentado significância estatística, o modelo explica 25,67\% da variação do preço do produto, o que é considerado baixo em comparação aos demais modelos realizados. Nenhuma das variáveis independentes do modelo apresentou significância estatística.

O décimo modelo de regressão toma o preço do óleo de soja como variável dependente, demonstrando uma significância estatística $(\mathrm{p}<0,010)$ que explica $66,74 \%$ da variação do preço do produto. Em relação às variáveis independentes, observa-se que apenas o tamanho dos mercados exerce influência significativa e negativa nos preços cobrados pelo óleo de soja, sendo assim, quanto maior o estabelecimento, menor o preço cobrado pelo produto. O décimo primeiro modelo utiliza o preço dos ovos de granja brancos como variável dependente. O modelo demonstrou significância estatística ( $\mathrm{p}<0,050$ ), explicando 52,70\% da variação do preço do produto pesquisado. No que se refere às variáveis independentes, verifica-se que a disponibilidade de entregas em domicílio e a distância do estabelecimento focal exercem influência significativa e positiva $(\mathrm{p}=0,007 \mathrm{e} \mathrm{p}=0,011$, respectivamente) no preço do óleo (décima primeira regressão). 
A décima segunda regressão, sendo o preço do sabão em pó a variável dependente, apresentou significância estatística $(\mathrm{p}<0,05)$ e explica $47 \%$ da variação do preço desse produto. Dentre as variáveis independentes do modelo, o tamanho do estabelecimento apresentou significância estatística $(p=0,005)$ e influência negativa sobre o preço, observando que estabelecimentos maiores cobram preços menores por esse produto. A décima terceira regressão múltipla tem o preço do sabonete como variável dependente, em que se constata um modelo significativo estatisticamente $(\mathrm{p}<0,05)$. Esse modelo explica $52,27 \%$ da variação do preço do sabonete. Ao analisar o impacto das variáveis independentes no preço do produto, verifica-se que apenas o tamanho dos estabelecimentos exerce influência significativa $(p=0,016)$ e negativa no preço. As outras duas variáveis independentes não apresentaram significância estatística.

O décimo quarto modelo de regressão, que tem como variável dependente o preço do xampu, não apresentou consistência estatística ( $\mathrm{p}=0,0533)$ e explica apenas $34,87 \%$ da variação do preço do produto. Analisando as variáveis independentes, verifica-se que apenas o tamanho dos estabelecimentos exerce influência negativa e significativa $(\mathrm{p}=0,047)$ nos preços cobrados pelo xampu. Logo, estabelecimentos menores tendem a cobrar mais pelo produto. O último modelo de regressão tem como variável dependente o preço do tomate longa vida. Esse modelo não apresentou significância estatística $(p=0,2139)$ e explica pouco $(13,91 \%)$ da variação do preço do tomate. Nenhuma variável independente do modelo obteve significância estatística, sendo assim, o modelo para esse produto não é considerado válido.

Uma análise geral das regressões múltiplas desta pesquisa demonstra que, dos preços dos 14 produtos pesquisados, o número de caixas (variável que avalia o tamanho dos estabelecimentos) é significativa para 10 produtos e influencia todos esses de forma negativa. Assim sendo, quanto maior o tamanho do mercado, menor é o preço observado dos produtos. Ao evidenciar a entrega em domicílio, verifica-se que a mesma é relevante apenas para o preço de três produtos, influenciando-os de forma positiva. Dessa forma, essa variável não apresentou grande relevância para a carteira de produtos pesquisados. A distância apresentou relevância estatística para quatro produtos, relatando-se uma influência positiva. Considera-se, portanto, que essa variável não influencia de forma expressiva a carteira de produtos.

\section{Considerações finais}

A partir da construção da literatura, no que diz respeito à organização industrial e ao modelo estrutura-conduta-desempenho, a qual embasa teoricamente esta pesquisa realizada no varejo supermercadista, observa-se que questões como o posicionamento geográfico, o tamanho dos estabelecimentos, as prá- 
ticas e os serviços disponibilizados influenciam nos preços praticados pelas empresas que atuam em uma estrutura de oligopólio. Infere-se que essas práticas e especificidades das empresas influenciam no seu desempenho econômico. Esta pesquisa envolve aspectos e características dos estabelecimentos supermercadistas pesquisados e a observação do impacto que essas características têm para os preços praticados pelos mesmos. Assim sendo, o foco maior é destinado para a conduta de mercado.

Sob a ótica da organização industrial, o presente trabalho corrobora com a ideia de que os grandes mercados atuam como líderes de preço, o que beneficia o consumidor uma vez que o mesmo pode adquirir dos fornecedores produtos a um preço menor. Por outro lado, os pequenos estabelecimentos apresentam certa dificuldade para concorrer via preço, pois não conseguem oferecer um preço competitivo ao se fazer comparação aos praticados pelos grandes mercados.

Os resultados desta pesquisa evidenciam que, à medida que aumenta a distância dos pequenos mercados dos estabelecimentos de grande porte, verifica-se um aumento dos preços praticados. Observou-se que o tamanho dos estabelecimentos é a variável mais impactante para os preços dos produtos. O serviço de entrega em domicílio e a distância do mercado focal, apesar de apresentarem significância estatística, não impactam no mesmo grau os preços dos produtos analisados. Possivelmente, esses resultados são decorrentes de economias de escala obtidas pelos estabelecimentos maiores e do volume de vendas realizado pelos mesmos.

Outra evidência é a constatação de que os produtos mais genéricos (cebola e tomate) não apresentaram modelos de regressões múltiplas significativos. Dessa forma, pode-se supor que o tamanho dos estabelecimentos, o serviço de entrega em domicílio e a distância dos mercados maiores não influenciam na variação do preço desses produtos. Em contrapartida, os resultados sugerem que produtos alimentícios de primeira necessidade apresentaram modelos de regressão mais consistentes. O açúcar, o arroz, o leite, a massa com ovos e o óleo de soja apresentaram modelos de regressão com coeficientes de determinação $\left(\mathrm{R}^{2}\right)$ maiores que o,6, ou seja, o tamanho dos estabelecimentos, a entrega em domicílio e a distância do mercado focal explicam mais de $60 \%$ da variação dos preços desses produtos. Esta pesquisa confirma, portanto, que o tamanho dos estabelecimentos é a variável que mais impacta nos preços praticados, seguido da distância do mercado focal. O serviço de entrega em domicílio é considerado como a variável independente menos importante dos modelos de regressão múltipla.

Esta pesquisa contribuiu para a melhor compreensão da dinâmica da concorrência no setor supermercadista em Porto Alegre/RS, ao passo que permitiu que uma nova agenda de pesquisas nessa área fosse estabelecida. Assim, sugere-se que novas pesquisas sejam realizadas, envolvendo questões: como se configura a formação de preços de produtos em supermercados em localidades com características distintas, ou seja, um bairro com baixo e 
outro com elevado produto interno bruto per capita, a fim de verificar se a política de preços difere ou se mantém a mesma em situações antagônicas. Outra questão que se coloca é que os preços sejam coletados mais de uma vez nos estabelecimentos, no intuito de avaliar a oscilação de preços em um determinado período de tempo. Sugere-se, ainda, que pesquisas qualitativas sejam empregadas para melhorar a compreensão sobre as motivações dos gestores das pequenas empresas em permanecerem atuando nesse setor e suas percepções sobre a concorrência.

\section{Referências}

ABRAS - Associação Brasileira de Supermercados. (2011). "As 5oo do ranking mostram a face do setor." URL [On line]: http://www.abrasnet.com.br/economia-e-pesquisa/ranking-abras/as-500-maiores/. Acesso em: 22 de janeiro de 2012.

AGAS - Associação Gaúcha de Supermercados. (2012). "Cesta AGAS." URL [On line]: http://www.agas.com.br/site/. Acesso em: 02 de janeiro de 2012.

BAIN, J. S. (1968). "Industrial organization." Berkeley: Wiley Edict, University of California.

BENITES, A. T. \& VALÉRIO, L. (2004). "Competitividade: uma abordagem do ponto de vista teórico.” In: JCEA, 4, Campo Grande, Anais... Campo Grande: UFMG, 2004, p. 01-09.

CYRILLO, D. C. (1987). “O papel dos supermercados no varejo de alimentos.” São Paulo: IPE-USP.

FARINA, E. M. M. (2000). Economia das organizações. In ZYLBERSZTAJN, D. \& NEVES, M. F. (orgs). Economia e gestão dos negócios agroalimentares. São Paulo: Pioneira, pp. 39-59.

FEE - Fundação de Economia e Estatística. (2012). "Estatísticas.” URL [On line]: http://www.fee.tche.br/sitefee/pt/content/estatisticas/. Acesso em: $13 \mathrm{de}$ janeiro de 2012.

FERGUSON, G. J. \& FERGUSON, P. R. (1994). "Industrial economics: issues and perspectives." New York: New York University Press.

FERREIRA, M. A. M. \& VENÂNCIO, M. M. \& ABRANTES, L. A. (2009). "Análise da eficiência do setor de supermercados no Brasil." Revista de Economia Aplicada 13(2): 333-47.

GILGil, A. C. (2010). Como elaborar projetos de pesquisa. São Paulo: Atlas.

HENDERSON, B. D. (1998). As origens da estratégia. In MONTGOMERY, C. A. \& PORTER, M. E. (orgs). Estratégia: a busca da vantagem competitiva. Rio de Janeiro: Campus.

IBGE - Instituto Brasileiro de Geografia e Estatística. (2012). "IBGE Cidades." URL [On line]: http://www.ibge.gov.br/cidadesat/topwindow.htm?1. Acesso em: 12 de janeiro de 2012.

KUPFER, D. \& HASENCLEVER, L. (2002). Economia industrial: fundamentos teóricos e práticos no Brasil. Rio de Janeiro: Campus. 
PARENTE, J. (2000). Varejo no Brasil: gestão e estratégia. São Paulo: Atlas.

PORTER, M. E. (1981). "The contributions of industrial organization to strategic management." Academy of Management Review 6 (4): 609-20.

. (1989). Vantagem competitiva: criando e sustentando desempenho superior. Rio de Janeiro: Campus.

PORTO ALEGRE - Prefeitura Municipal. (2012). Planejamento: bairros oficiais. URL [On line]: http://www.portoalegre.rs.gov.br/. Acesso em: o5 de eiróiro de 2012.

POSSAS, M. L. (1985). Estruturas de mercado em oligopólio. São Paulo: Hucitec.

ROJO, F. J. G. (1998). "Qualidade total: uma nova era para os supermercados.” Revista de Administração de Empresas 38(4): 26-36.

Recebido em: 13 de outubro de 2012 Aceito em : 06 de junho de 2013 